\title{
O RISCO DE ESVAZIAMENTO \\ DA LEGITIMIDADE DEMOCRÁTICA \\ HABERMASIANA DA JURISDIÇÃO \\ CONSTITUCIONAL BRASILEIRA
}

\author{
ORLANDO SAMPAIO SILVA ${ }^{\dagger}$ \\ FLÁVIA PESSOA ${ }^{\dagger \dagger}$
}

RESUMO: O presente artigo analisa a tensão constante existente entre jurisdição constitucional e democracia à luz de uma teoria discursiva que preconize um processo aberto de interpretação, no que concerne especificamente ao controle concentrado de constitucionalidade realizado pelo Supremo Tribunal Federal. O estudo busca criticar a insuficiência de uma legitimação democrática da jurisdição constitucional com base apenas em decisões bem fundamentadas, a se erigir um conceito de legitimidade discursiva através de uma discussão racional e comunitária. Indaga-se a respeito da existência, ou não, de tal forma de legitimação no Brasil e até que ponto isso pode vir a se tornar um subterfúgio retórico. A temática é abordada pelo método dedutivo, por meio de pesquisa doutrinária e jurisprudencial. $\mathrm{O}$ artigo pretende, ao fim, demonstrar que há um longo caminho a se percorrer até que se possa falar verdadeiramente em uma legitimidade democrática pluralista da jurisdição constitucional exercida pelo Supremo Tribunal Federal.

\section{PALAVRAS-ChAVE: Jurisdição Constitucional; Legitimidade} Democrática; Neoconstitucionalismo; Pluralismo.

\footnotetext{
${ }^{\dagger}$ Mestrando em Direito pela Universidade Federal de Sergipe (UFS) e Defensor Público.

${ }^{\dagger}$ Doutora em Direito Público, Mestre em Direito, Estado e Cidadania, Professora do Mestrado em Direito da Universidade Federal de Sergipe (UFS) e do Mestrado em Direitos Humanos da Universidade Tiradentes (UNIT), Juíza do Trabalho no Tribunal Regional do Trabalho da Vigésima Região e Líder do Grupo de Pesquisa $A$ Hermenêtica Constitucional Concretizadora dos Direitos Fundamentais e Reflexos nas Relações Sociais da UFS.
} 
ABSTRACT: This article analyzes the tension between judicial review and democracy on the bases of a discursive theory, which prioritize an open process of interpretation. The study shows the failure of a democratic legitimation of judicial review only lined on well motivated decisions. The objective is to inquire about the existence, or not, in Brazil, of a rational and communitarian discursive legitimation. The issue is addressed by the deductive method, through doctrinal and jurisprudential research. The article aims to demonstrate that Brazil needs to improve the mechanisms of popular representation on judicial review. Only then, we can talk about a democratic and pluralistic legitimation.

KEYWORDS: Judicial Review; Democratic Legitimacy;

Neoconstitutionalism; Pluralism. 


\section{SUMÁRIO:}

I. INTRODUÇ̃̃ 0 .......................................................................................598

II. NeOCONSTITUCIONALISMO, JURISDIÇão CONSTITUCIONAL

E A PROMESSA DE UMA DEMOCRACIA CONSTITUCIONAL ................599

III. EM BUSCA DE UM CONCEITO DE DEMOCRACIA................................606

IV. O RISCO DE ESVAZIAMENTO DA LEGITIMIDADE DEMOCRÁtICA DA JURISDIÇão CONSTITUCIONAL BRASILEIRA ................................611

V. CONSIDERAÇõés FinaIS.................................................................618

VI. REFERÊNCIAS..................................................................................619

\section{TABLE OF CONTENTS:}

I. INTRODUCTION ....................................................................................598

II. NeOCONSTITUTIONALISM, JUdiCial REVIEW AND THE CONSTITUTIONAL DEMOCRACY PROMISE.........................599

III. LOOKING FOR A CONCEPT OF DEMOCRACY......................................606

IV. The DEMOCRATIC LegitimaCy OF BRaZILIAN JUdicial REVIEW RISK OF EMPTYING .................................................................................611

V. FINAL CONSIDERATIONS ...............................................................618

VI. REFERENCES ..................................................................................619 


\section{INTRODUÇÃO}

A celeuma a respeito da legitimidade democrática da jurisdição constitucional configura tema discutido incessantemente, sobretudo porque remanesce a corrente de entendimento segundo a qual a atuação do Legislativo teria preponderância pelo fato de ser composto por representantes eleitos pelo povo. Contudo, o movimento neoconstitucionalista, ao alocar a Constituição no centro do ordenamento jurídico, conferiu à jurisdição constitucional um protagonismo nunca antes visto, o que acirrou a controvérsia do debate.

Nessa nova conjuntura, a tradicional noção de que a legitimidade dos provimentos jurisdicionais em controle de constitucionalidade decorreria de fundamentos transparentes e racionais, passíveis de refutação objetiva, não se mostrava mais suficiente. A apresentação, na estrutura decisória, de motivos coerentes não era bastante para que se justificasse a invalidação de normas criadas pelos representantes de uma teórica vontade da maioria. Começou-se a se falar em uma abertura do processo interpretativo das normas constitucionais, a possibilitar a participação ativa da sociedade.

Sendo assim, o presente trabalho possui o escopo de analisar criticamente a aplicação efetiva, ou não, de uma teoria discursiva de abertura no exercício da jurisdição constitucional. Examinar-se-á em que medida se pode afirmar que os debates, em processos objetivos julgados pelo Supremo Tribunal Federal (STF), de fato, assimilam a pluralidade de opiniões comunitárias ao ponto de se conceber uma legitimidade discursiva tal como idealizada por Jürgen Habermas.

A temática é palpitante, pois cada vez mais questões de singular relevância social têm sido submetidas à Suprema Corte Brasileira, o que desperta a necessidade de uma discussão a respeito dos contornos democráticos da jurisdição constitucional por ela desempenhada.

Para alcançar a meta proposta, o presente trabalho se divide em três partes, afora sua conclusão ao final, tendo sido utilizado o método dedutivo referente à pesquisa bibliográfica. ${ }^{1}$ Em sua primeira parte, $\mathrm{o}$ trabalho apresenta as relações entre o neoconstituconalismo e a jurisdição constitucional, bem como a possibilidade de uma democracia constitucional, a fim de situar a origem teórica e filosófica do tema central.

${ }^{1}$ A referida pesquisa se deu com base em exame da jurisprudência do STF, assim como dos dispositivos legais da Lei oํ 9.868/1999, especificamente aqueles relativos ao amicus curiae e à audiência pública. Foram objeto de análise a ADPF no 101/DF, a ADI $\mathrm{n}^{\mathrm{o}}$ 3.510/DF e o HC no ${ }^{\mathrm{o}}$ 126.292/SP. 
Na segunda, busca-se construir uma visão de democracia que permita uma jurisdição constitucional eficaz e passível de ser legitimada.

Na terceira, adentra-se o âmago do presente trabalho, o qual se refere ao risco de se transformar o argumento da legitimidade discursiva, no viés habermasiano, em um mero artifício retórico. Por fim, cuida-se das conclusões finais do trabalho.

\section{NEOCONSTITUCIONALISMO, JURISDIÇÃO CONSTITUCIONAL E A PROMESSA DE UMA DEMOCRACIA CONSTITUCIONAL}

Precisar conceitualmente o que vem a ser o neoconstitucionalismo constitui uma verdadeira aporia. Não há nada perto de um consenso a respeito de sua definição, bem como, sobretudo, acerca dos juristas que supostamente integrariam o também denominado pós-positivismo, visto o dissenso de formas de pensar esse novo paradigma da teoria constitucional. Por isso, a formulação aqui apresentada se reveste menos de um rigor etimológico e mais de um objetivo de delimitação do objeto de estudo. $\mathrm{O}$ foco, portanto, reside em seus marcos filosófico e teórico. ${ }^{2}$

O neoconstitucionalismo configura um movimento jurídico-filosófico que, dentre outros elementos, rompeu o paradigma ortodoxo da hermenêutica constitucional. "Representa consequência do esgotamento das categorias de interpretação propostas pelo positivismo jurídico, mormente em relação ao seu legicentrismo." ${ }^{3} \mathrm{Com}$ a escusa tipicamente atribuída àqueles que interpretam a história anos a frente dos fatos analisados, pode-se afirmar que o neoconstitucionalismo foi uma consequência inexorável das distorções ocasionadas sob a égide do paradigma positivista. Se a transição da Escola Exegética para a Jurisprudência dos Valores se mostrou inevitável, ante o descompasso entre interpretação como mera reprodução da norma e a realidade fática, $\mathrm{o}$ mesmo se pode dizer a respeito da inexorabilidade do advento do movimento neconstitucionalista. A crença de uma Constituição como mero conjunto de pretensões futuras sem coercitividade não supria a irresignação contra um Direito que, embora atrelado à noção de justiça, era constantemente assacado para oprimir.

${ }^{2}$ Cf. BARROSO, Luís Roberto. Neoconstitucionalismo e Constitucionalização do Direito: o Triunfo Tardio do Direito Constitucional no Brasil. Themis: Revista da ESMEC, Vol. 4, 2, 2006.

${ }^{3}$ SAMPAIO, José Adércio Leite. Teoria da Constituição e dos Direitos Fundamentais. Belo Horizonte, MG: Del Rey, 2013, p. 183. 
No que concerne ao marco histórico, é cediço que as atrocidades cometidas nos diversos regimes totalitários, a exemplo do fascismo, na Itália, e do nazismo, na Alemanha, alicerçaram-se em um ordenamento jurídico que as legitimavam formalmente. Tratou-se, indubitavelmente, de Estados de Direito de Exceção. É sempre oportuno lembrar que concepções substancialistas ou de formalismo ético, nas quais se inviabiliza o debate a respeito de uma justificação externa do Direito, têm o potencial de culminar em conjunturas totalitárias. ${ }^{4}$ Não se pode legitimar o Direito unicamente com base na norma positivada, sob pena de se endossar circunstâncias tétricas com arrimo legal.

Como consequência, na segunda metade do século $\mathrm{XX}$, houve o fenômeno da reconstitucionalização, a redimensionar o lugar da Constituição no ordenamento jurídico e na comunidade política como um todo. ${ }^{5}$ A Constituição já era vista como um documento jurídico, mas destituída da coercitividade intrínseca às normas jurídicas em geral. Viase a Constituição como um simples protocolo de intenções políticas, as quais, no máximo, corporificariam vetores axiológicos ao processo legiferante. ${ }^{6}$ Por sua vez, a legislação ordinária era enaltecida cegamente

${ }^{4}$ FERRAJOLI, Luigi. Direito e Razão: Teoria Do Garantismo Penal. $2^{\underline{a}}$ ed. Trad. Ana Paula Zomer Sica et. al. São Paulo, SP: Editora Revista dos Tribunais, 2006, p. 145.

${ }^{5}$ Cf. BARROSO, Luís Roberto. Constituição, Democracia e Supremacia Judicial: Direito e Política no Brasil Contemporâneo. Revista da Faculdade de Direito da UERJ, No. 21, 2012. Disponível em: $<\underline{\text { http://www.e- }}$ publicacoes.uerj.br/index.php/rfduerj/article/view/1794>. Acesso em: 27 de julho de 2017.

${ }^{6}$ A concepção da norma constitucional enquanto norma jurídica e, portanto, revestida de coercitividade não é exclusiva do neoconstitucionalismo. O positivismo jurídico, ao se contrapor ao jusnaturalismo do século XVI, equiparou o Direito à lei. Ao se considerar o constitucionalismo como movimento histórico-filosófico de limitação do poder, seja ele constituído pelo povo ou, inclusive, fruto de uma cadeia hierárquica, o mesmo se tornaria inviável caso se mantivesse estática a ideia de Constituição. Ao se falar em constitucionalismo, não apenas o moderno - gênese da Constituição escrita o texto constitucional passa a ser visto não como um documento estritamente político, mas também um conjunto normativo dotado de eficácia jurídica e social. Cf.

BARROSO, Luís Roberto. Neoconstitucionalismo e Constitucionalização do Direito: o Triunfo Tardio do Direito Constitucional no Brasil. Themis: Revista da ESMEC, Vol. 4, 2, 2006. De outro lado, o neoconstitucionalismo possui, como marco filosófico, o póspositivismo, sendo que, neste, há traços do jusnaturalismo moderno e do positivismo. Basicamente, transcende-se a visão restrita a elementos metafísicos - típica do jusnaturalismo - e se passa a explorar categorias normativas. Conquanto questões 
ao ponto de se ter a visão de que seria unicamente ela a veicular direito e sistematizar o Estado. Com esse novo papel da Constituição no âmago do sistema jurídico, tanto sob uma perspectiva de validade como também de justiça, o texto constitucional ganha destaque e passa a demandar uma nova hermenêutica. É precisamente nesse ponto em que emergem os pontos de destaque desse tópico: o marco filosófico e o marco teórico.

No primeiro deles, destaca-se o pós-positivismo como referencial teórico. Trata-se de superação do debate secular entre positivistas e justanturalistas. Em um primeiro momento, o jusnaturalismo moderno propugnava uma aproximação entre lei e razão, ou seja, entre Direito e elementos extrajurídicos apreensíveis pela racionalidade humana. Conquanto tenha servido de força motriz às revoluções liberais, teve seu ocaso no final do século XIX.7 Foi justamente nesse momento histórico em que se sobreleva o paradigma epistemológico científico, o que mais tarde alicerçaria, no Direito, o modelo positivista.

Com efeito, o paradigma epistemológico científico, consolidado na segunda metade do século XIX, ainda é cegamente replicado nos dias atuais. Essa concepção cientificista concebe a produção do conhecimento a partir da dicotomia sujeito e objeto (S-O), em que o sujeito cognoscente remanesce inerte ao observar o objeto cognoscível. ${ }^{8}$

A revolução científica, ocorrida entre os séculos XVI e XVIII, fez a humanidade testemunhar a grandeza do saber humano. Copérnico, com o seu heliocentrismo, ao fulminar as concepções rígidas da época que

axiológicas relativas ao conceito de justiça não sejam rechaçadas por completo, passam a ser atreladas à imperatividade normativa, ou seja, norma enquanto modelos coercitivos de comportamento. Cf. BARROSO, Luís Roberto. Neoconstitucionalismo e Constitucionalização do Direito: o Triunfo Tardio do Direito Constitucional no Brasil. Themis: Revista da ESMEC, Vol. 4, 2, 2006. Portanto, a noção de Constituição como norma não é restrita ao neoconstitucionalismo, mas sim a construção de uma nova hermenêutica constitucional, a qual se funda na constatação de que a norma constitucional, nada obstante sua natureza de norma jurídica, requer mecanismos interpretativos diferenciados. Cf. SOUZA NETO, Cláudio Pereira de; SARMENTO, Daniel. Direito Constitucional: Teoria, História e Métodos de Trabalho. Belo Horizonte, MG: Editorial Fórum, 2012.

${ }^{7}$ Cf. BARROSO, Luís Roberto. Judicialização, Ativismo Judicial e Legitimidade Democrática. 2008. Disponível em: $<$ http://www.migalhas.com.br/arquivo artigo/art20090130-01.pdf $>$. Acesso em: 27 de julho de 2017.

${ }^{8}$ SANTOS, Boaventura de Sousa. Um Discurso sobre as Ciências. $4^{\mathrm{a}}$ ed. São Paulo, SP: Cortez, 2006, p. 134. 
colocavam a Terra como centro do universo, e Isaac Newton, ao redimensionar a mecânica clássica com suas três leis, são apenas alguns exemplos desse momento histórico. Todavia, não apenas as descobertas da ciência foram exaltadas, mas, também, o método utilizado para que fossem alcançadas, qual seja, o método científico. Passou-se a entender que somente o método científico seria capaz de produzir um conhecimento verdadeiro e objetivo. ${ }^{9}$

Como dito, no campo do Direito, o citado método científico se fez presente no positivismo jurídico, visto que esse origina-se do esforço de conformar o estudo do Direito em uma ciência similar àquelas de conteúdo físico-matemático, natural e social. Essa corrente de pensamento pregava, fundamentalmente uma postura passiva do intérprete, a abstrair qualquer ímpeto criativo, bem como excluía da análise do Direito quaisquer elementos axiológicos, de forma que, nessa ótima, tratar-se-ia de uma ciência cujo objeto de estudo seria a norma enquanto integrante de um ordenamento. ${ }^{10}$

Todavia, conforme já asseverado, a perspectiva positivista, tal como o jusnaturalismo do século XVI, restou estar rechaçado por conta dos deploráveis eventos históricos ocorridos.

O pós-positivismo reaproxima o Direito da Moral, afinal já havia ficado mais do que claro que aquele não se autojustificava e, portanto, se mostrou inevitável o recurso a elementos extrajurídicos. Nessa perspectiva, o texto constitucional naturalmente se destacou por conta de sua textura flexível e aberta, sobretudo ante a presença de princípios, a comportar maiores ponderações a respeito de aspecto meta-jurídicos. Seria por meio da Constituição que se empreenderia uma mudança no Direito como um todo, porquanto seu texto comportava um maior diálogo por parte do intérprete, com a Moral e, por conseguinte, com a própria justificação do direito positivo.

No momento em que se atesta a força normativa de princípios como o do Estado Democrático de Direito, da dignidade da pessoa humana e da solidariedade social, abrem-se as portas para o debate de cunho moral a respeito dos institutos jurídicos. ${ }^{11}$ No entanto, resulte-se que não há uma dissolução total da divisão entre Direito e Moral, mas sim, pela primeira

9 SCHMIDT, Lawrence. Hermenêutica. Trad. Fábio Ribeiro. Petrópolis, RJ: Vozes, 2013, p. 230 .

${ }^{10}$ BOBBIO, Norberto. Teoria do Ordenamento Jurídico. 10ª ed. Brasília, DF: UnB, 1999, p. 135.

${ }^{11}$ Cf. SARMENTO, Daniel. Livres e Iguais: Estudos de Direito Constitucional. Rio de Janeiro, RJ: Lumen Juris, 2006.

3 JOURNAL OF INSTITUTIONAL STUDIES 1 (2017) 
vez, após longos anos, um intercâmbio entre as duas searas.

Em relação ao marco teórico, destaca-se a expansão da jurisdição constitucional como consectário imediato desse novel protagonismo da Constituição. Considerando-se seu novo papel fundante do sistema jurídico, nada mais natural que a ampliação do controle de constitucionalidade da legislação ordinária, justamente para salvaguardar a eficácia das normas constitucionais. ${ }^{12}$

Nessa perspectiva, o Poder Judiciário passa a ser dotado de inegável destaque, visto que caberá a ele aferir, por meio da jurisdição constitucional, a compatibilidade da legislação ordinária com a Constituição. É rigorosamente nesse aspecto que subsiste a perene tensão entre jurisdição constitucional e democracia, visto que, no seu exercício, o Judiciário pode vir a declarar a invalidade de normas advindas do consenso procedimentalizado de representantes do povo.

Em uma concepção rasa de democracia, as leis ordinárias seriam fruto da vontade da maioria, porquanto concretizadas mediante processo legislativo integrado por representantes eleitos democraticamente. Essas leis, em última instância, seriam emanações do próprio povo. Por outro lado, a legislação infraconstitucional não possibilitava, em regra, divagações axiológicas em seu processo interpretativo, o que produzia injustiças. Com a proeminência do texto constitucional, volta-se atenção ao seu rol de direitos e garantias fundamentais.

O enaltecimento da jurisdição constitucional não é mero acaso. É através dela que se protegem e concretizam os referidos direitos fundamentais enquanto posições jurídicas de maior importância do indivíduo..$^{13}$ Os direitos fundamentais mais do que garantias de situações

${ }^{12}$ Cf. Cf. BARROSO, Luís Roberto. Neoconstitucionalismo e Constitucionalização do Direito: o Triunfo Tardio do Direito Constitucional no Brasil. Themis: Revista da ESMEC, Vol. 4, 2, 2006.

${ }^{13}$ A jurisdição constitucional possibilita a realização dos diversos direitos fundamentais elencados no texto constitucional, visto que permite o controle judicial dos atos dos Poderes Executivo e Legislativo com alicerce nas normas constitucionais. Contudo, fatores de caráter econômico também influenciam a concretização de tais direitos. É justamente nessa seara que se verifica um dos aspectos de tensão democrática no âmbito da jurisdição constitucional. Dito de outro modo, na medida em que o Judiciário cria uma obrigação ao Poder Público, com o escopo de que este cumpra o dever de efetivar os direitos fundamentais, ao mesmo tempo interfere na discricionariedade orçamentária. Outrossim, limitação orçamentária não reflete somente nos chamados direitos de segunda dimensão, visto que, sob a perspectiva da indivisibilidade dos direitos fundamentais, todo direito fundamental reclama, em 
jurídicas subjetivas, representa o próprio fundamento axiológico do ordenamento, a nortear a interpretação e a gênese normativa na função legiferante. ${ }^{14}$ Por seu intermédio, fulminam-se normas que venham a ferir esses direitos ou a reafirmar sua vigência e eficácia no ordenamento jurídico.

Por outro lado, a jurisdição constitucional traz consigo outro problema, qual seja, a (in)segurança decorrente da ênfase concedida aos princípios em face de uma nova hermenêutica constitucional. Assim, por mais que se tenha partido da ideia de que a força normativa da Constituição se alicerçaria no caráter jurídico das normas constitucionais, a interpretação destas se revestiria de categorias próprias. ${ }^{15} \mathrm{O}$ texto constitucional, em regra, é mais poroso e, portanto, demanda do intérprete uma postura mais ativa e inovadora. Lidar com princípios, definitivamente, requer um ato interpretativo consideravelmente mais complexo se comparados às normas-regra. Os princípios, portanto, seriam, no mais das vezes, valores e opções axiológicas, diferentemente das normas jurídicas. ${ }^{16}$

No entanto, os aplausos direcionados à fundamentação das decisões em postulados principiológicos estavam condicionados ao alicerce das mesmas no Direito como um todo, de forma a racionalizá-las, a constituir outro aspecto tornado relevante com o neoconstitucionalismo: a argumentação jurídica. Para evitar arbítrios judiciais, conjecturou-se uma teoria da argumentação para balizar a atuação do interprete nessa empreitada principiológica. A Tópica Viehwegiana, a Retórica de Perelman, a Argumentação Jurídica como Caso Especial de Alexy, inclusive, o Romance em Cadeia de Dworkin representaram esforços no sentido de tornar o mais objetivo possível essa nova hermenêutica

alguma medida, dispêndio material por parte do Estado. Cf. RAMOS, André de Carvalho. Teoria Geral dos Direitos Humanos na Ordem Internacional. $2^{\underline{a}}$ ed. São Paulo, SP: Saraiva, 2012.

${ }^{14}$ SARLET. Ingo Wolfgang. A Eficácia dos Direitos Fundamentais: uma Teoria Geral dos Direitos Fundamentais na Perspectiva Constitucional. 12 ${ }^{a}$ ed. Porto Alegre, RS: Livraria do Advogado, 2015, p. 322.

${ }^{15}$ BARCELLOS, Ana Paula de. Neoconstitucionalismo, Direitos Fundamentais e Controle das Políticas Públicas. Revista de Direito Administrativo, No. 240, 2005, p. 101.

${ }^{16}$ SAMPAIO, José Adércio Leite. Teoria da Constituição e dos Direitos

Fundamentais. Belo Horizonte, MG: Del Rey, 2013, p. 186. 
constitucional. ${ }^{17}$

Nesse prisma, há duas vertentes sobre a legitimidade da jurisdição constitucional. A primeira concerne à chamada legitimidade discursiva do Poder Judiciário, segundo a qual as decisões judiciais se legitimam não por meio da representatividade inerente ao Legislativo, mas mediante a argumentação racional. Refere-se a uma legitimação oriunda de um discurso racional propagador de valores comunitários. Assim, tendo em vista que a aferição de constitucionalidade, por vezes, comporta uma série de entendimentos possíveis, os fundamentos das decisões judiciais se mostram consistentes a partir de um confronto discursivo. ${ }^{18}$

A legitimidade, nesse ponto, estaria na motivação, por parte do magistrado, das decisões de controle de constitucionalidade com base em argumentos transparentes e coerentes, mormente para viabilizar a refutação. Todavia, as críticas ferrenhas à invalidação de atos legislativos pelo Judiciário continuaram e trouxeram a necessidade de um novo viés de legitimação. Por isso, construiu-se uma teoria da contramajoritariedade dos provimentos jurisdicionais em controle de constitucionalidade. Ao se invalidar normas ordinárias ante a declaração de inconstitucionalidade, impede-se a perpetuação de uma ditadura da maioria. Conquanto o Legislativo seja composto por representantes eleitos, as normas ordinárias não se justificam simplesmente por serem emanadas por aquele poder. Dessarte, a reaproximação entre Direito e Moral, obstaculizou o expediente da autojustificação, inclusive no âmbito do Poder Legislativo.

A jurisdição constitucional, ao garantir a salvaguarda dos direitos fundamentais, age verdadeiramente em nome da vontade popular, visto que preservará as posições jurídicas mais essenciais. ${ }^{19} \mathrm{O}$ Judiciário, em

${ }^{17}$ Cf. SAMPAIO, José Adércio Leite. Teoria da Constituição e dos Direitos

Fundamentais. Belo Horizonte, MG: Del Rey, 2013, p. 195; VIEHWEG, Theodor.

Tópica e Jurisprudência. Trad. Tércio Sampaio Ferraz Jr. Brasília, DF: Departamento de Imprensa Nacional, 1979; PERELMAN, Chaïm; OLBRECHTS-TYTECA, Lucie.

Tratado da Argumentação: a Nova Retórica. $2^{\underline{a}}$ ed. Trad. Maria Ermantina de Almeida Prado Galvão. São Paulo, SP: Martins Fontes, 2005; ALEXY, Robert. Teoria da

Argumentação Jurídica: a Teoria do Discurso Racional como Teoria da

Fundamentação Jurídica. $3^{a}$ ed. Trad. Zilda Hutchinson Schild Silva. Rio de Janeiro, RJ: Forense, 2013; e DWORKIN, Ronald. Levando os Direitos à Serio. $2^{\underline{a}}$ ed. Trad.

Jefferson Luiz Camargo. São Paulo, SP: Martins Fontes, 2007.

18 FERRAZ JÚNIOR, Tércio Sampaio. Introdução ao Estudo do Direito: Técnica, Decisão, Dominação. $7^{\mathrm{a}}$ ed. São Paulo, SP: Atlas, 2013, p. 149.

${ }^{19}$ ALEXY, Robert. Teoria dos Direitos Fundamentais. Trad. Virgílio Afonso da Silva. São Paulo, SP: Malheiros Editores, 2008, p. 54. 
sede de aferição da constitucionalidade das leis, abre uma porta para o debate acerca das concepções sociais do texto constitucional e permite um consenso, o qual confere legitimidade democrática à jurisdição constitucional. Nesse raciocínio, o Poder Judiciário funcionaria como amplificador das concepções sociais e, com base também nelas, analisaria a compatibilidade formal e material dos atos legislativos ante os dispositivos constitucionais.

É justamente nesse viés que se defende uma democracia constitucional fruto de uma jurisdição constitucional efetiva. Democracia por se tratar de dar voz a uma comunidade por meio de um espaço comunicativo perante o Judiciário. Com efeito, para que se possa chegar no ponto central desse trabalho se mostra imprescindível, em tópico subsequente, a delimitação dos conceitos de democracia, a fim de que se precise aquele que se coaduna com a ideia a ser defendida.

\section{EM BUSCA DE UM CONCEITO DE DEMOCRACIA}

Não se está a buscar as raízes históricas do conceito de democracia muito menos uma denominação abstrata precisa. $\mathrm{O}$ que se quer, no presente tópico, é entender a democracia enquanto fenômeno político compatível com a Constituição e, também, com a jurisdição constitucional. Nessa linha, um dos aspectos consolidados pelo neoconstitucionalismo foi o debate acerca de vertentes formal e material de cada instituto jurídico, de modo que não poderia ser diferente com a definição de democracia à luz do Direito.

Em uma concepção formal, democracia significa a concretização legítima da vontade de uma maioria mediante mecanismos procedimentais previamente estipulados, a exemplo do que acontece no processo eleitoral brasileiro. Embora importante, não se pode conceber mormente no Brasil uma noção de democracia estritamente formal. Como se sabe, no Estado Brasileiro é vigente a chamada democracia semidireta ou participativa, na qual se mesclam atributos representativos e de participação direta do povo. Em uma ótica meramente formal, uma vez tendo ocorrido o regular encerramento do processo eleitoral, os atos legislativos produzidos pelos representantes eleitos corporificariam a vontade dessa maioria. Todavia, trata-se de uma ideia, no mínimo, ingênua.

Dois fatores são cruciais para que se perceba a insuficiência de um conceito formal de regime democrático. $O$ primeiro se refere à corrupção tão noticiada nos dias atuais, a qual se capilarizou consideravelmente, a 
produzir influxos sobre grande parte das instâncias de poder. Nessa perspectiva, não se pode afirmar que os congressistas brasileiros priorizam os interesses da maioria dos cidadãos em face de pretensões de outra ordem, tais como as partidárias e as econômicas. O segundo se refere à atuação incansável dos denominados grupos de pressão, os quais exercem lobby contínuo junto aos parlamentares. Contudo, tais grupos se referem a categorias específicas, o que significa que nem de longe possuem a representatividade intrínseca a um modelo democrático. ${ }^{20}$

Fica claro, por conseguinte, que o argumento de uma vontade da maioria veiculada pelos representantes eleitos é falacioso, a despertar a necessidade de uma concepção material ou substancial de democracia. Sob a ótica substancial, a democracia se relaciona com os direitos fundamentais, sendo estes verdadeiros limitadores do conteúdo das decisões legislativas. Significa dizer que, por mais que formalmente válidos, os atos produzidos pelos representantes eleitos podem vir a apresentar incongruências materiais se vulnerarem direitos e garantias fundamentais. Em um Estado Social, também não podem os congressistas quedarem-se inertes diante de determinadas questões que deverão ser objeto de legislação, o que configuraria um vício legislativo pela inércia. ${ }^{21}$ Consectariamente, o conceito de democracia deve englobar tanto a procedimentalização das decisões dos representantes, como também um conteúdo harmônico com os direitos fundamentais.

Não se pode, entretanto, visualizar a democracia como algo estanque. No enfoque aqui defendido, cidadão e cidadania deixam de ser vistos somente como atributos dos eleitores, mas como a qualidade de ser humano portador de dignidade e titular de direitos fundamentais. Os cidadãos não recebem de seus representantes as soluções e prestações de serviços, mediante apoio ou reprovação no período eleitoral, mas são coparticipes de projeto mútuo de vida, de modo a permanecerem politicamente ativos entre uma eleição e outra. A vontade popular, portanto, não é algo empírico e verificável por meio de pesquisa de opinião, sem que haja uma discussão consistente sobre seu conteúdo, nem uma vontade despótica. O povo representa uma pluralidade de valores e pontos de vista, de forma que não há de se falar em um querer

${ }^{20}$ ZAMPIERI, Enio. Ação dos Grupos de Pressão no Processo Decisório das Comissões Permanentes do Congresso Nacional. E-Legis, Vol. 6, 12, 2013, p. 105. Disponível em: $<$ http://bd.camara.gov.br/bd/bitstream/handle/bdcamara/16179/acao grupos zampieri. pdf? sequence $=2>$. Acesso em: 17 de julho de 2017 .

${ }^{21}$ FERRAJOLI, Luigi. Direito e Razão: Teoria Do Garantismo Penal. $2^{a}$ ed. Trad. Ana Paula Zomer Sica et. al. São Paulo, SP: Editora Revista dos Tribunais, 2006, p. 233. 
popular absoluto. ${ }^{22}$

Em outro viés, a vontade popular, enquanto confluência factível de uma pluralidade de visões de mundo, apenas pode ser aferida legitimamente por intermédio de um ambiente discursivo e comunicativo. Com isso, uma democracia alicerçada em representação política demanda a possibilidade de uma racionalidade discursiva e popular pautada nos direitos fundamentais. ${ }^{23} \mathrm{~A}$ efetivação dos direitos fundamentais, nesse contexto, não prescinde de uma participação popular no processo deliberativo através de procedimentos discursivos estipulados. Afinal, é inafastável a necessidade de se dar voz àqueles que mais têm interesse em sua concretização. Desse modo, o Poder Legislativo não substitui materialmente a vontade popular, nem, muito menos, tem a prerrogativa, conquanto eleito, de dispor do texto constitucional. ${ }^{24}$

O caráter discursivo deve integrar o conceito de democracia, ou seja, o que se está a apresentar não é uma mera espécie de regime democrático, mas a essência de qualquer democracia. Uma vez assimilada a discussão como forma racional e compartilhada de se construir soluções, a democracia torna-se deliberativa. Nessa situação, o discurso é institucionalizado, a significar que os próprios pontos de vista plurais são conduzidos ao cerne do Estado para fins de processo decisório. ${ }^{25}$ Essa ótica de democracia se amolda harmonicamente com a noção ortodoxa de legitimidade discursiva do Judiciário, segundo a qual os provimentos jurisdicionais seriam legitimados desde que racional e consistentemente motivados. Diante do exposto, as decisões judiciais se tornam democraticamente legítimas contanto que presentes fundamentos socialmente reconhecidos, não como certos em si mesmos, mas como

22 SAMPAIO, José Adércio Leite. Teoria da Constituição e dos Direitos

Fundamentais. Belo Horizonte, MG: Del Rey, 2013, p. 72.

${ }^{23}$ ALEXY, Robert. Teoria dos Direitos Fundamentais. Trad. Virgílio Afonso da Silva. São Paulo, SP: Malheiros Editores, 2008, p. 145.

${ }^{24}$ OLIVEIRA, Marcelo Andrade Cattoni de. Jurisdição e hermenêutica constitucional no estado democrático de direito: um ensaio de teoria da interpretação enquanto teoria discursiva da argumentação jurídica de aplicação. In: Marcelo Andrade Cattoni de Oliveira. Jurisdição e Hermenêutica Constitucional: no Estado Democrático de Direito. Belo Horizonte, MG: Mandamentos, 2004, p. 10.

${ }^{25}$ Cf. MARINONI, Luiz Guilherme. Da Teoria da Relação Jurídica Processual ao

Processo Civil do Estado Constitucional. 2012. Disponível em

$<$ http://www.abdpc.org.br/abdpc/artigos/Luiz\%20G\%20Marinoni(8)\%20-

\%20formatado.pdf $>$. Acesso em: 15 de julho de 2017. 
razoáveis. Não se trata da apreensão onírica, pelo julgador, de uma vontade metafísica da comunidade, mas a capacidade de trazer ao processo cognitivo a multiformidade de opiniões presente na sociedade.

Nessa senda, destaca-se a teoria discursiva de Habermas. O autor alemão concebe uma democracia procedimental, na qual a legitimidade das decisões produzidas pelo Poder Público, em todas as suas instâncias, depende da viabilização de um ambiente discursivo identificado pela livre circulação de ideias. ${ }^{26}$ Portanto, plenamente possível à utilização da teoria discursiva harbesiana para atribuir legitimidade democrática às decisões consubstanciadas em sede de jurisdição constituição.

O prisma retrógrado segundo o qual os Tribunais Constitucionais não teriam legitimidade para invalidar atos legislativos supostamente irradiados de uma instância majoritária é deixado para trás. Constata-se que as Cortes terão legitimidade desde que abram suas portas à sociedade para que esta possa participar ativamente do deslinde decisório. Não se trata de uma busca utópica por um consenso, mas sim por decisões pautadas em uma racionalidade discursiva. ${ }^{27}$

Há, ainda, o conceito de patriotismo constitucional também trabalhado por Habermas que se coaduna com sua teoria discursiva. $\mathrm{O}$ patriotismo constitucional se refere a uma autorreferência por parte dos indivíduos de uma comunidade no sentido de se perceberem como titulares de direitos fundamentais previstos na Constituição e, portanto, legítimos para atuarem das instâncias deliberativas. Por mais que situados em uma conjuntura multicultural, os cidadãos se identificam mutuamente como destinatários de situações jurídicas fundamentais de base constitucional, a significar um elemento aglutinador. ${ }^{28}$ Afinal, nada mais justo que os principais titulares dos direitos fundamentais possam integrar os debates a respeito destes.

Demais disso, o patriotismo constitucional se relaciona com o chamado sentimento constitucional, expressão cunhada por Pablo Lucas Verdú, que significa a possibilidade de uma determinada comunidade política acreditar tenazmente na vigência, eficácia e justiça das normas

${ }^{26}$ HABERMAS, Jürgen. Direito e Democracia: entre Facticidade e Validade, Vol. 2.

Trad. Flávio Beno Siebeneichler. Rio de Janeiro, RJ: Tempo Brasileiro, 2003, p. 139.

${ }^{27}$ HABERMAS, Jürgen. Direito e Democracia: entre Facticidade e Validade, Vol. 2.

Trad. Flávio Beno Siebeneichler. Rio de Janeiro, RJ: Tempo Brasileiro, 2003, p. 153.

${ }^{28}$ OLIVEIRA, Marcelo Andrade Cattoni de. Jurisdição e hermenêutica constitucional no estado democrático de direito: um ensaio de teoria da interpretação enquanto teoria discursiva da argumentação jurídica de aplicação. In: Marcelo Andrade Cattoni de Oliveira. Jurisdição e Hermenêutica Constitucional: no Estado Democrático de Direito. Belo Horizonte, MG: Mandamentos, 2004, p. 147. 
constitucionais. ${ }^{29}$ Assim, um povo que busca perpetuar seus valores por meio de um discurso racional empreendido nas instâncias do poder é aquele dotado de patriotismo e sentimento constitucionais.

Nesses termos, subsistem aspectos condicionantes para que se possa falar em uma legitimidade democrática da jurisdição constitucional. É indispensável que o Judiciário oportunize uma seara comunicativa na qual os indivíduos, sob o viés coletivo, se pronunciem a respeito de suas formas de pensar. Há, também, a imperiosidade de um patriotismo e sentimentos constitucionais aflorados, a fim de que a comunidade se pronuncie efetivamente na seara contramajoritária do controle de constitucionalidade dos atos legislativos. Dessarte, o Poder Judiciário, em sede de jurisdição constitucional, não estará a derrogar a vontade da maioria, mas, em verdade, atribuirá à atividade legislativa uma atualização necessária em face do suporte axiológico contemporâneo. É por meio dessa abertura discursiva que se poderá verificar, com maior segurança, qual, de fato, é a vontade da maioria, caso ela realmente exista.

O jurista Peter Häberle já concebia, em sua sociedade aberta dos intérpretes da Constituição, uma democracia constitucional de cunho discursivo. $^{30}$ Para ele, coexistiriam no processo de interpretação constitucional, intérpretes formalmente previstos em lei e aqueles informais. Em uma sociedade pluralista, tal concepção mais do que possível é inevitável, visto que, ante sua multiformidade, a legitimação democrática das decisões emanadas dos intérpretes oficiais da Constituição demanda um campo de debate. Por sua vez, o autor Konrad Hesse concebeu a definição de abertura constitucional por conduto da qual os diversos projetos de vida existentes pudessem coexistir e compartilhar, a priori, da proteção conferida pela Constituição. ${ }^{31}$

29 VERDÚ, Pablo Lucas. O Sentimento Constitucional: aproximações ao estudo do Sentir Constitucional como modo de Integração Política. Trad. Agassiz Almeida Filho. Rio de Janeiro, RJ: Forense, 2004, p. 179.

${ }^{30}$ Cf. HÄBERLE, Peter. Hermenêutica Constitucional: a Sociedade Aberta dos Intérpretes da Constituição. Contribuição para a Interpretação Pluralista e "Procedimental" da Constituição. Trad. Gilmar Ferreira Mendes. Porto Alegre, RS: Sergio Antonio Fabris Editor, 1997.

${ }^{31}$ Cf. SAMPAIO, José Adércio Leite. Teorias Constitucionais em Perspectiva: em busca de uma Constituição Pluridimensional. In: José Adércio Leite Sampaio (Org.). Crises e Desafios da Constituição: Perspectivas Críticas da Teoria e das Práticas Constitucionais Brasileiras. Belo Horizonte, MG: Del Rey, 2004; e HESSE, Konrad. A Força Normativa da Constituição. Trad. Gilmar Ferreira Mendes. Porto Alegre, RS: Sérgio Antonio Fabris, 1991. 
Conclui-se que a legitimidade democrática da jurisdição constitucional, seja sob o prisma contramajoritário a salvaguardar direitos fundamentais de uma ditadura de uma hipotética maioria, seja também sob a égide de uma teoria discursiva de pluralidade de intérpretes da Constituição, requer a concreta existência de um espaço de argumentação coletiva, sendo esta pautada em um patriotismo constitucional. Entretanto, no Brasil, especificamente no que tange à atuação do STF no exercício da jurisdição constitucional, a sua legitimidade democrática corre sério risco de vir a se tornar um artifício de retórica.

Nesses termos, o próximo tópico versará sobre o risco de um esvaziamento da legitimação democrática da atuação da Corte Constitucional Brasileira, o que tornaria a referência a anseios sociais, em decisões de fiscalização de constitucionalidade, puro sofisma.

\section{O RISCO DE ESVAZIAMENTO DA LEGITIMIDADE DEMOCRÁTICA DA JURISDIÇÃO CONSTITUCIONAL BRASILEIRA}

Na obra O Caso dos Exploradores de Caverna, do autor Lon Fuller, o magistrado Handy, ao expor o seu voto, apresenta dois argumentos interessantes. ${ }^{32} \mathrm{O}$ primeiro se refere a uma ponderação no sentido de que os seres humanos são bem governados desde que seus governantes compreendam seus sentimentos, sendo que, de todos os ramos do governo, seria o Judiciário aquele mais suscetível a se distanciar do homem comum. Em seguida, ao se referir a uma enquete acerca da opinião pública sobre o destino dos réus, assevera que o resultado da pesquisa seria despiciendo, porquanto aferível pelo simples bom senso. Explicita-se, nesse trecho da citada obra, uma advertência concernente ao afastamento entre sociedade e Judiciário, assim como à ilusão de que se

${ }^{32}$ Cf. FULLER, Lon. O Caso dos Exploradores de Cavernas. Trad. Ricardo Rodrigues Gama. Campinas, SP: Russel, 2013. Cumpre ressaltar que a obra em comento se insere no gênero de ficção jurídica. Destarte, cada integrante do tribunal, na história, representa uma vertente teórica do pensamento jurídico. A seu turno, o magistrado Handy se remete ao realismo jurídico, segundo o qual a sabedoria prática deve subsidiar suas decisões, de forma que, com base na instrumentalidade do formalismo processual, preconiza o contato pragmático do Judiciário com a opinião pública. Cf. GODOY, Arnaldo Sampaio de Moraes. Lon Fuller e o Caso dos Exploradores das Cavernas. 2012. Disponível em: <http://www.conjur.com.br/2012-mar-18/embargosculturais-lon-fuller-exploradores-cavernas $>$. Acesso em: 24 de julho de 2017. 
podem detectar os valores sociais apenas pelo bom senso.

Com o advento da Lei $\mathrm{n}^{\mathrm{o}}$ 9.868/1999, a regular a jurisdição constitucional já prevista no Texto Magno de 1988, erigiram-se novos institutos pertinentes ao controle concentrado de constitucionalidade, realizado, sobretudo, pelo STF. Destacam-se os institutos do amicus curiae e da audiência pública, os quais invariavelmente se ligam à legitimação democrática das decisões construídas pela Corte Constitucional.

$\mathrm{O}$ amicus curiae, de raiz no norte-americana, viabiliza o ingresso, no processo objetivo, de entidades representativas, com o desiderato de apresentar seus pontos de vista, não necessariamente ligadas à defesa de um ou outro posicionamento contraposto no processo. A seu turno, a audiência pública é manejada com o objetivo de se clarificar, perante o Tribunal, temáticas de natureza econômica, técnica, administrativa e jurídica. ${ }^{33}$

Na discussão a respeito de pesquisas científicas com células-tronco embrionárias, na ADI no 3.510/ DF, a Suprema Corte Brasileira convocou, mediante decisão proferida pelo relator Carlos Ayres Britto, em 19 de dezembro de 2006, a primeira audiência pública a ser realizada no âmbito daquele tribunal. ${ }^{34}$ Desde então, tanto as audiências públicas, como a figura do amicus curiae, têm permeado os julgamentos de processos objetivos pelo STF. Um outro exemplo foi a ADPF no 101/DF, em que o Pretório Excelso, após ouvir, em audiências públicas, especialistas em saúde, comércio exterior e meio ambiente, limitou a importação de pneus usados no país. ${ }^{35}$ Para se chegar a tal decisão, o plenário da Corte ponderou temáticas essencialmente distintas, a envolver questões econômicas, ambientais e de sustentabilidade. Ademais, quando do julgamento de uma série de ações relativas à saúde, a Suprema Corte reuniu aproximadamente cinquenta especialistas entre Advogados, Defensores Públicos, Promotores, Magistrados, Professores, Médicos, entre outros profissionais. ${ }^{36}$

Essa conexão entre a Corte Constitucional e a sociedade é inegavelmente positiva, e assim tem sido vislumbrada. Por isso, vêm-se

${ }_{33}$ Cf. BUENO, Cássio Scarpinella. Amicus Curiae no Processo Civil Brasileiro: um

Terceiro Enigmático. $3^{\text {a }}$ ed. São Paulo, SP: Saraiva, 2012, p. 75.

${ }^{34}$ Cf. STF, ADI nº 3.510/DF, Tribunal Pleno, Min. Rel. Ayres Britto. Julgamento em: 29/05/2008.

${ }^{35}$ Cf. STF, ADPF no 101/DF. Tribunal Pleno, Min. Rel. Cármen Lúcia. Julgamento em: 24/06/2009.

${ }^{36}$ Cf. STF, SL no 47/PE, Presidência do STF, Min. Gilmar Mendes. Julgamento em: 17/03/2010 (julgamento conjunto). 
utilizando, largamente, esses mecanismos de abertura, a exemplo dos casos relativos ao aborto de fetos anencefálicos, a problemas do Sistema Único de Saúde e ações afirmativas. ${ }^{37}$ Isso representa uma pluralização das discussões travadas no STF, o que permite o reconhecimento democrático de sua força institucional, consolidando-se como instância essencial à democracia. ${ }^{38}$

Destarte, tem-se por enaltecida a legitimidade discursiva na medida em que, ao permitir o influxo de argumentos provenientes da comunidade, o STF se mostra apto a produzir decisões racionais e de fundamentação consistente. $\mathrm{O}$ estreitamento dos vínculos entre o Tribunal e a sociedade justifica sua função contramajoritária, visto que analisa a legislação ordinária também à luz de óticas socialmente compartilhadas.

E evidente que o debate pluralista acerca da interpretação constitucional, de forma semelhante à sociedade aberta dos intérpretes idealizada por Peter Haberle, é algo a se enaltecer, afinal a legitimidade resultante é salutar. ${ }^{39} \mathrm{Na}$ prática, entretanto, há o sério risco de que a argumentação levada aos autos dos processos de controle de constitucionalidade pela comunidade não venham a integrar, efetivamente, o debate dos Ministros da Suprema Corte Brasileira.

Em um ponto inicial, destaque-se que a representatividade das entidades ingressas no processo objetivo, na condição de amicus curiae ou mediante audiências públicas, não é claramente definida. Não há critérios minimamente objetivos para que se afira o grau de representação desses entes, de maneira que atestar que estariam a representar a multiformidade de visões comunitárias se mostra temerário.

O aproveitamento dos argumentos trazidos ao STF também é uma questão tormentosa. Não há como saber se o que foi exposto em audiência pública, de fato, foi compreendido e concretamente considerado no processo cognitivo dos Ministros. Por exemplo, na mencionada ADI n⿳o

${ }^{37}$ Cf. STF, ADPF no 54/DF, Tribunal Pleno, Min. Rel. Marco Aurélio de Mello. Julgamento em: 12/04/2012; STF, SL no 47/PE, Presidência do STF, Min. Gilmar Mendes. Julgamento em: 17/03/2010 (julgamento conjunto); e STF, ADPF no 186/DF, Tribunal Pleno, Min. Rel. Ricardo Lewandowski. Julgamento em: 25/04/2012.

${ }^{38}$ Cf. MENDES, Gilmar Ferreira. Direitos Fundamentais e Controle de

Constitucionalidade: Estudos de Direito Constitucional. $4^{\mathrm{a}}$ ed. São Paulo, SP: Saraiva, 2012.

${ }^{39}$ HÄBERLE, Peter. Hermenêutica Constitucional: a Sociedade Aberta dos Intérpretes da Constituição. Contribuição para a Interpretação Pluralista e "Procedimental" da Constituição. Trad. Gilmar Ferreira Mendes. Porto Alegre, RS: Sergio Antonio Fabris Editor, 1997.

3 JOURNAL OF INSTITUTIONAL STUDIES 1 (2017) 
3.510/DF, apenas quatro Ministros do STF compareceram à audiência pública, sendo que apenas um deles remanesceu até o final da sessão. Acrescente-se a ausência, em parte dos votos, de referência expressa às proposições explanadas na citada audiência. ${ }^{40}$

Por outro lado, atente-se para o fato de o povo brasileiro não vivenciar, atualmente, os fenômenos do patriotismo e do sentimento constitucionais. Se, por um lado, o neoconstitucionalismo trouxe consigo a própria (re)constitucionalização do Direito, a resultar em uma filtragem constitucional na interpretação de seus ramos, de outro, a confiança na Constituição não tem sido propalada entre os cidadãos brasileiros. Os infindáveis esquemas de corrupção que afetam todas as instâncias, somados ao não cumprimento das promessas da Constituição Social, produziram uma descrença geral na Lei Maior de 1988. ${ }^{41}$ Dentro desse contexto, de que modo se pode falar em um discurso racional e participativo na senda da jurisdição constitucional? Como defender, obstinadamente, a legitimidade democrática do controle de constitucionalidade empreendido pelo STF nos moldes demonstrados? Em suma, não se pode conceber que, em um processo de discussão blindado, ante a grande parte da comunidade, bem como em um ambiente sem crença na efetividade dos direitos fundamentais, não se pode falar, de fato, em uma interpretação democrática das normas constitucionais.

O professor Paulo Bonavides, ao se debruçar sobre a temática da abertura do processo interpretativo da constituição, já prevenia que isso demandaria um sólido consenso democrático, uma base social estável, pressupostos institucionais firmes e uma cultura política bem desenvolvida, qualidades estas que não estão presentes no Brasil. ${ }^{42}$ Por conseguinte, como conceber a existência inequívoca da pretendida legitimidade democrática do processo decisório típico da jurisdição constitucional?

Nesse ponto, um esclarecimento é oportuno. Não se está a repelir

${ }^{40}$ Cf. MARONA, Marjorie Corrêa; ROCHA, Marta Mendes da. As Audiências Públicas do Supremo Tribunal Federal: ampliando sua Legitimidade Democrática? Teoria \&

Sociedade, Vol. 22, 1, 2014. Disponível em:

$<\underline{\text { http://www.waporbh.ufmg.br/ revistasociedade/index.php/rts/article/viewFile/145/1 }}$ 10>. Acesso em: 15 de julho de 2017.

${ }^{41}$ SAMPAIO, José Adércio Leite. Teoria da Constituição e dos Direitos

Fundamentais. Belo Horizonte, MG: Del Rey, 2013, p. 67.

${ }^{42}$ BONAVIDES, Paulo. Curso de Direito Constitucional. 18ª ed. São Paulo, SP:

Malheiros, 2006, p. 605. 
qualquer legitimação democrática do controle de constitucionalidade exercido pelo STF, principalmente porque não se descura do fato de a defesa dos direitos fundamentais, como elementos axiológicos aglutinadores do ordenamento, apresentar indubitável viés democrático. ${ }^{43}$ É a partir da proteção e consubstanciação desses direitos que se dá a função contramajoritária do Judiciário, o que é indubitavelmente uma representação democrática. Não uma democracia estritamente formal e pautada no sofisma da prevalência da vontade majoritária, mas uma democracia constitucional, na qual os vários projetos de vida são agasalhados pela jurisdição constitucional através da representatividade dos direitos e garantias fundamentais.

Entretanto, não se pode acrescentar ao argumento da legitimidade democrática aquele atinente à abertura discursiva da jurisdição constitucional no STF, ao menos não de forma incondicional. A limitada circunstância da presença de amicus curiae e a realização de audiências públicas, por si sós, não confere uma áurea inquestionável de legitimidade discursiva, sob a ótica habermasiana, às decisões da Corte Brasileira. É imperiosa a avaliação da efetividade desses mecanismos em situações concretas.

Há, ainda, de se examinar as referências feitas por Ministros, em sede de processos subjetivos, a pretensões de natureza social. Para exemplificar, cumpre mencionar os debates no âmbito do julgamento do $\mathrm{HC} \mathrm{n}^{\mathrm{o}}$ 126.292/SP, a respeito da prisão em decorrência de condenação em segundo grau de jurisdição em face da presunção de inocência estatuída no art. $5^{2}$, inciso LVII, da Constituição Federação de $1988 .{ }^{44}$ Neles, chegouse a invocar, como subsídio para a decisão pela relativização da presunção de inocência na segunda instância, a expectativa social resultante de uma suposta impunidade pelo excesso de interposições recursais. Conquanto não se trate de um processo objetivo, claramente há uma distorção do conceito de legitimidade democrática apresentada.

Diante dessa declaração, o professor Aury Lopes oportunamente questiona a que expectativas exatamente correspondeu o mencionado julgamento: seriam sociais, políticas ou econômicas? ${ }^{45}$ Além disso, como

${ }^{43}$ SARLET. Ingo Wolfgang. A Eficácia dos Direitos Fundamentais: uma Teoria Geral dos Direitos Fundamentais na Perspectiva Constitucional. 12 ${ }^{a}$ ed. Porto Alegre, RS:

Livraria do Advogado, 2015, p. 567.

${ }^{44}$ Cf. STF, HC no 126.292/SP, Tribunal Pleno, Min. Rel. Teori Zavascki. Julgamento em: $17 / 02 / 2016$.

${ }^{45}$ Cf. LOPES JR., Aury. Fim da presunção de inocência pelo STF é nosso 7 a 1 jurídico. 2016. Disponível em: <http://www.conjur.com.br/2016-mar-04/limite-penalfim-presuncao-inocencia-stf-nosso-juridico>. Acesso em: 15 de julho de 2017. 
se daria, nesses casos, a gestão dessas expectativas? São ponderações que não foram, de forma alguma, ventiladas quando da referência a essa democratização da decisão a respeito da presunção de inocência.

Como foi dito, não se pode defender uma irrefletida legitimação democrática apenas diante da existência de instrumentos de abertura do debate em sede de processos de controle de constitucionalidade no STF. Por outro lado, também não se pode admitir, como premissa irrefutável, que a Corte Constitucional tem a capacidade de apreender a pluralidade axiológica da sociedade por meio do exercício da jurisdição constitucional. Os instrumentos de abertura argumentativa, na jurisdição constitucional, ainda necessitam evoluir muito para que se possa falar em uma participação comunitária.

E nem se encampa a tese de que aquele Tribunal deveria ser capaz de extrair algum consenso ante a diversidade de opiniões da comunidade, dada a total impossibilidade de tal pretensão. Por outro lado, o raciocínio da legitimidade democrática, em um prisma de racionalidade discursiva, não pode se transformar em um artifício de retórica, a gerar a falsa percepção de que votos e decisões são exarados sempre com respaldo nos anseios sociais. Diante de tal contexto, há dois caminhos possíveis.

$\mathrm{O}$ primeiro se refere ao aperfeiçoamento dos mecanismos de participação democrática nos processos de controle de constitucionalidade, com a finalidade de que as entidades, admitidas como amicus curiae ou ouvidas em audiência pública, verdadeiramente representem contingentes sociais. Além disso, deve ocorrer a idealização de instrumentos que confiram peso, no curso da cognição de cada Ministro, aos argumentos apresentados, não de forma determinante, mas como pontos a serem apreciados. Após a lapidação desses instrumentos de participação, aí sim será viável se falar em decisões que cotejaram expectativas comunitárias.

Dessa forma, no momento de convocação de audiências públicas, não se podem perder de vista certos parâmetros. Conquanto o art. 9, $\S 1^{\underline{a}}$, da Lei no 9.868/1999 estatua que as audiência públicas almejam a oitiva de autoridades e especialistas sobre a matéria objeto de julgamento, não há de se descurar de seu caráter democrático. As audiências públicas representam, também, a oportunidade de participação social na discussão em busca de elementos imprescindíveis a decisão judicial a ser prolatada.

As audiências públicas, assim como o ingresso processual de amici curiae, portanto, se utilizadas de forma satisfatória, podem conferir legitimidade democrática à jurisdição constitucional exercida. Para tanto, não se deve limitar a participação a especialistas, de forma que se viabilize a inscrição do público em geral, por meio de critérios de 
representatividade, em sua realização. Embora seja impossível a participação de todos, prestigiar entidades de representação civil se mostra promissor no que diz respeito ao conhecimento dos valores socialmente compartilhados. ${ }^{46}$

Por conseguinte, a escolha dos participantes das audiências públicas deve consagrar seu nível de representatividade social. Outrossim, outro parâmetro a ser respeitado, tanto em relação às audiências públicas, como no que tange aos amici curiae, é a interação consistente com os ministros julgadores. De nada adianta a presença de órgãos e entidades de envergadura representativa se os argumentos apresentados não forem considerados pela Corte Constitucional na construção decisória. Desse modo, é imprescindível um ambiente discursivo no qual as associações civis, de fato, dialoguem com os ministros, os quais, para tanto, deverão se fazer presentes nas audiências públicas e por ocasião da oitiva do amicus curiae.

O segundo caminho, lado outro, é evitar a referência imprecisa de valores sociais nas decisões. Ao se constatar a inviabilidade, mesmo que momentânea, de um contato real com as visões de mundo pulverizadas na comunidade, não há de se criar, a partir disso, tautologias com o objetivo de obter convencimento em relação ao conteúdo decisório.

Reitere-se que, consoante já foi aduzido, há tantos outros elementos legitimadores das decisões, em jurisdição constitucional, prolatadas pelo STF, o que significa que não se suprime o caráter democrático de sua atuação. O viés contramajoritário e de legitimidade pautada na fundamentação consistente e racional continuarão a existir, por mais que, no momento atual, não se possa conceber a aplicação efetiva da teoria discursiva habermasiana como outro elemento legitimador da jurisdição constitucional. Diferentemente do que expôs a personagem do magistrado Handy, por mais evidente que algumas questões pareçam ser, o bom senso jamais pode ser invocado como forma racional de se extrair os diversos pontos de vista que premiam a comunidade.

${ }^{46}$ Cf. FERRAZ, Anna Candida da Cunha. A Projeção da Democracia Participativa na Jurisdição Constitucional no Brasil: as Audiências Públicas e sua adoção no Modelo Concentrado de Constitucionalidade. In: Carlos Bastide Horbach, Fernando Dias Menezes de Almeida, José Levi Mello do Amaral Júnior e Roger Stiefelmann Leal (Orgs.). Direito Constitucional, Estado de Direito e Democracia: Homenagem ao Prof. Manoel Gonçalves Ferreira Filho. São Paulo, SP: Quartier Latin, 2011. 


\section{CONSIDERAÇões FinAIS}

O neoconstitucionalismo, ao revitalizar o papel das normas constitucionais no sistema jurídico, trouxe uma série de novos questionamentos, como foi o caso da proteção judicial desses dispositivos e a vertente democrática típica da atuação legislativa. Se, por um lado, o objetivo geral era garantir a efetividade da Constituição, por outro, olhava-se com certa desconfiança a invalidação de normas ordinárias por um poder, em tese, sem representatividade.

Ao invés de técnicas hermenêuticas específicas para a extração do significado normativo, a prioridade, nesse contexto, era a formulação de uma teoria da argumentação jurídica, precisamente para possibilitar o controle das decisões judiciais, sobretudo em face da utilização massiva de princípios nas mesmas. Em um primeiro momento, os provimentos jurisdicionais dotados de motivação consistente eram tidos, por essas circunstâncias, como legitimados. Inclusive, argumentava-se que essa legitimação também seria democrática, visto que, ao se salvaguardar os direitos fundamentais em face de uma pretensa vontade da maioria, preservavam-se os grupos minoritários.

No entanto, em um cenário de ineficiência dos demais poderes, a jurisdição constitucional se tornou cada vez mais recorrente, a demandar novos ideais de legitimação. Assim, gestou-se a ideia de uma legitimação discursiva e pluralista, corolário da participação da sociedade nos debate que integram o controle de constitucionalidade.

Dentro dessa perspectiva, destacaram-se os institutos do amicus curiae e da audiência pública, nos processos objetivos julgados pelo STF, e a pretensão de uma legitimação discursiva nos moldes idealizados por Habermas. ${ }^{47}$ Questionou-se, por conseguinte, até que ponto a comunidade participa da cognição da Corte Constitucional, seja sob a ótica da representatividade das entidades que ingressam nesses processos, assim como sob o prisma do peso dos argumentos apresentados. Demonstrou-se, assim, que, na prática, não há uma clara legitimidade discursiva e pluralista no processo de interpretação constitucional no STF.

Sendo assim, refutou-se a assimilação autômata da noção de que a previsão de mecanismos de abertura, nos processos de jurisdição constitucional, já significaria uma legitimidade democrática pautada na pluralidade de intérpretes da Constituição, tal como conceberam

${ }^{47}$ Cf. HABERMAS, Jürgen. Direito e Democracia: entre Facticidade e Validade, Vol.

2. Trad. Flávio Beno Siebeneichler. Rio de Janeiro, RJ: Tempo Brasileiro, 2003. 
Häberle, Habermas e tantos outros. ${ }^{48}$ É imprescindível a verificação constante da efetividade desse processo de abertura à comunidade, de forma que esta, de fato, participe das decisões em controle de constitucionalidade realizado pelo STF.

\section{REFERÊNCIAS}

ALEXY, Robert. Teoria da Argumentação Jurídica: a Teoria do Discurso Racional como Teoria da Fundamentação Jurídica. $3^{\text {a }}$ ed. Trad. Zilda Hutchinson Schild Silva. Rio de Janeiro, RJ: Forense, 2013.

. Teoria dos Direitos Fundamentais. Trad. Virgílio Afonso da Silva. São Paulo, SP: Malheiros Editores, 2008.

BARCELLOS, Ana Paula de. Neoconstitucionalismo, Direitos Fundamentais e Controle das Políticas Públicas. Revista de Direito Administrativo, No. 240, 2005.

BARROSO, Luís Roberto. Constituição, Democracia e Supremacia Judicial: Direito e Política no Brasil Contemporâneo. Revista da Faculdade de Direito da UERJ, No. 21, 2012. Disponível em: $<$ http://www.e-publicacoes.uerj.br/index.php/rfduerj/article/view/1794 $>$. Acesso em: 27 de julho de 2017.

BARROSO, Luís Roberto. Judicialização, Ativismo Judicial e Legitimidade Democrática. 2008. Disponível em: $<$ http://www.migalhas.com.br/arquivo artigo/art20090130-01.pdf $>$. Acesso em: 27 de julho de 2017.

${ }^{48}$ Cf., entre outros, HÄBERLE, Peter. Hermenêutica Constitucional: a Sociedade Aberta dos Intérpretes da Constituição. Contribuição para a Interpretação Pluralista e "Procedimental" da Constituição. Trad. Gilmar Ferreira Mendes. Porto Alegre, RS: Sergio Antonio Fabris Editor, 1997; e HABERMAS, Jürgen. Direito e Democracia: entre Facticidade e Validade, Vol. 2. Trad. Flávio Beno Siebeneichler. Rio de Janeiro, RJ: Tempo Brasileiro, 2003. 
BARROSO, Luís Roberto. Neoconstitucionalismo e Constitucionalização do Direito: o Triunfo Tardio do Direito Constitucional no Brasil.

Themis: Revista da ESMEC, Vol. 4, 2, 2006.

BOBBIO, Norberto. Teoria do Ordenamento Jurídico. 10ª ed. Brasília, DF: UnB, 1999.

BONAVIDES, Paulo. Curso de Direito Constitucional. 18ª ed. São Paulo, SP: Malheiros, 2006.

BUENO, Cássio Scarpinella. Amicus Curiae no Processo Civil

Brasileiro: um Terceiro Enigmático. 3ª̣ ed. São Paulo, SP: Saraiva, 2012.

DWORKIN, Ronald. Levando os Direitos à Serio. $2^{\mathrm{a}}$ ed. Trad. Jefferson Luiz Camargo. São Paulo, SP: Martins Fontes, 2007.

FERRAJOLI, Luigi. Direito e Razão: Teoria Do Garantismo Penal. $2^{a}$ ed. Trad. Ana Paula Zomer Sica et. al. São Paulo, SP: Editora Revista dos Tribunais, 2006.

FERRAZ, Anna Candida da Cunha. A Projeção da Democracia Participativa na Jurisdição Constitucional no Brasil: as Audiências Públicas e sua adoção no Modelo Concentrado de Constitucionalidade. In: Carlos Bastide Horbach, Fernando Dias Menezes de Almeida, José Levi Mello do Amaral Júnior e Roger Stiefelmann Leal (Orgs.). Direito Constitucional, Estado de Direito e Democracia: Homenagem ao Prof. Manoel Gonçalves Ferreira Filho. São Paulo, SP: Quartier Latin, 2011.

FERRAZ JÚNIOR, Tércio Sampaio. Introdução ao Estudo do Direito: Técnica, Decisão, Dominação. $7^{a}$ ed. São Paulo, SP: Atlas, 2013.

FULLER, Lon. O Caso dos Exploradores de Cavernas. Trad. Ricardo Rodrigues Gama. Campinas, SP: Russel, 2013. 
GODOY, Arnaldo Sampaio de Moraes. Lon Fuller e o Caso dos Exploradores das Cavernas. 2012. Disponível em:

$<$ http://www.conjur.com.br/2012-mar-18/embargos-culturais-lon-fullerexploradores-cavernas $>$. Acesso em: 24 de julho de 2017.

HÄBERLE, Peter. Hermenêutica Constitucional: a Sociedade Aberta dos Intérpretes da Constituição. Contribuição para a Interpretação Pluralista e "Procedimental" da Constituição. Trad. Gilmar Ferreira Mendes. Porto Alegre, RS: Sergio Antonio Fabris Editor, 1997.

HABERMAS, Jürgen. Direito e Democracia: entre Facticidade e Validade, Vol. 2. Trad. Flávio Beno Siebeneichler. Rio de Janeiro, RJ: Tempo Brasileiro, 2003.

HESSE, Konrad. A Força Normativa da Constituição. Trad. Gilmar Ferreira Mendes. Porto Alegre, RS: Sérgio Antonio Fabris, 1991.

LOPES JR., Aury. Fim da presunção de inocência pelo STF é nosso 7 a 1 jurídico. 2016. Disponível em: $<$ http://www.conjur.com.br/2016-mar04/limite-penal-fim-presuncao-inocencia-stf-nosso-juridico $>$. Acesso em: 15 de julho de 2017.

MENDES, Gilmar Ferreira. Direitos Fundamentais e Controle de Constitucionalidade: Estudos de Direito Constitucional. $4^{a}$ ed. São Paulo, SP: Saraiva, 2012.

MARINONI, Luiz Guilherme. Da Teoria da Relação Jurídica Processual ao Processo Civil do Estado Constitucional. 2012.

Disponível em

$<$ http://www.abdpc.org.br/abdpc/artigos/Luiz\%20G\%20Marinoni(8)\%20 -\%20formatado.pdf $>$. Acesso em: 15 de julho de 2017. 
MARONA, Marjorie Corrêa; ROCHA, Marta Mendes da. As Audiências Públicas do Supremo Tribunal Federal: ampliando sua Legitimidade Democrática? Teoria \& Sociedade, Vol. 22, 1, 2014. Disponível em: $<$ http://www.waporbh.ufmg.br/ revistasociedade/index.php/rts/article/ viewFile/145/110>. Acesso em: 15 de julho de 2017.

OLIVEIRA, Marcelo Andrade Cattoni de. Jurisdição e hermenêutica constitucional no estado democrático de direito: um ensaio de teoria da interpretação enquanto teoria discursiva da argumentação jurídica de aplicação. In: Marcelo Andrade Cattoni de Oliveira. Jurisdição e Hermenêutica Constitucional: no Estado Democrático de Direito. Belo Horizonte, MG: Mandamentos, 2004.

PERELMAN, Chaïm; OLBRECHTS-TYTECA, Lucie. Tratado da Argumentação: a Nova Retórica. $2^{a}$ ed. Trad. Maria Ermantina de Almeida Prado Galvão. São Paulo, SP: Martins Fontes, 2005.

RAMOS, André de Carvalho. Teoria Geral dos Direitos Humanos na Ordem Internacional. 2 ${ }^{\underline{a}}$ ed. São Paulo, SP: Saraiva, 2012.

\section{SAMPAIO, José Adércio Leite. Teoria da Constituição e dos Direitos} Fundamentais. Belo Horizonte, MG: Del Rey, 2013.

SAMPAIO, José Adércio Leite. Teorias Constitucionais em Perspectiva: em busca de uma Constituição Pluridimensional. In: José Adércio Leite Sampaio (Org.). Crises e Desafios da Constituição: Perspectivas Críticas da Teoria e das Práticas Constitucionais Brasileiras. Belo Horizonte, MG: Del Rey, 2004.

SANTOS, Boaventura de Sousa. Um Discurso sobre as Ciências. $4^{\underline{a}}$ ed. São Paulo, SP: Cortez, 2006. 
SARLET. Ingo Wolfgang. A Eficácia dos Direitos Fundamentais: uma Teoria Geral dos Direitos Fundamentais na Perspectiva

Constitucional. 12 ${ }^{\underline{a}}$ ed. Porto Alegre, RS: Livraria do Advogado, 2015.

SARMENTO, Daniel. Livres e Iguais: Estudos de Direito

Constitucional. Rio de Janeiro, RJ: Lumen Juris, 2006.

SCHMIDT, Lawrence. Hermenêutica. Trad. Fábio Ribeiro. Petrópolis, RJ: Vozes, 2013.

SOUZA NETO, Cláudio Pereira de; SARMENTO, Daniel. Direito Constitucional: Teoria, História e Métodos de Trabalho. Belo Horizonte, MG: Editorial Fórum, 2012.

VERDÚ, Pablo Lucas. O Sentimento Constitucional: aproximações ao estudo do Sentir Constitucional como modo de Integração Política. Trad. Agassiz Almeida Filho. Rio de Janeiro, RJ: Forense, 2004.

VIEHWEG, Theodor. Tópica e Jurisprudência. Trad. Tércio Sampaio Ferraz Jr. Brasília, DF: Departamento de Imprensa Nacional, 1979.

ZAMPIERI, Enio. Ação dos Grupos de Pressão no Processo Decisório das Comissões Permanentes do Congresso Nacional. E-Legis, Vol. 6, 12, 2013, p. 105. Disponível em:

$<$ http://bd.camara.gov.br/bd/bitstream/handle/bdcamara/16179/acao gr upos zampieri.pdf?sequence=2>. Acesso em: 17 de julho de 2017 .

O Risco de Esvaziamento da Legitimidade Democrática Habermasiana da Jurisdição Constitucional Brasileira The Habermasian Democratic Legitimacy of Brazilian Judicial Review Risk of Emptying Submetido em: 2017-05-15 Aceito em: 2017-07-29 